\title{
Peroral endoscopic pyloromyotomy for delayed postoperative gastroparesis
}

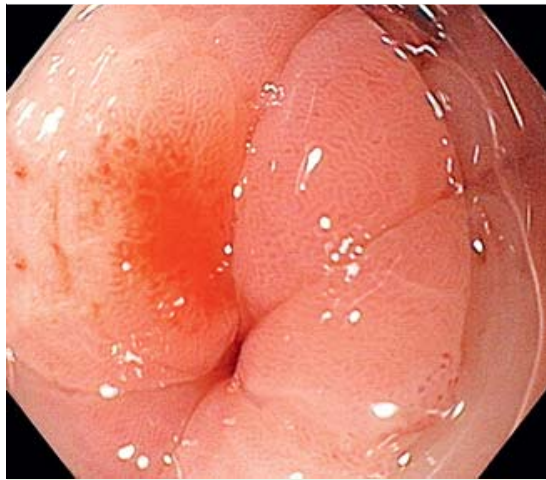

Fig. 1 Endoscopic view of the tight pylorus in a patient with delayed gastroparesis following laryngopharyngectomy for laryngeal cancer.

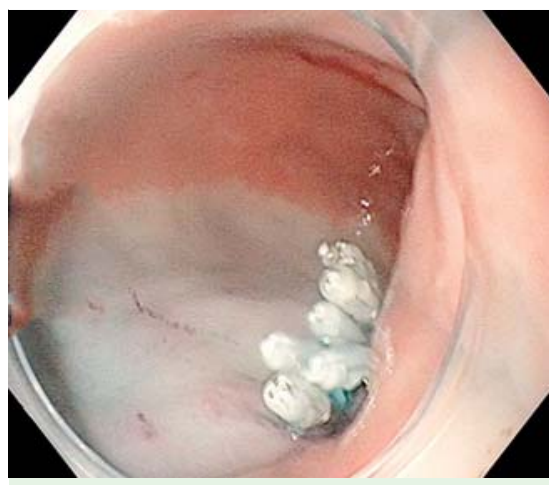

Fig. 4 Mucosal closure with endoclips.

Functional gastric outlet obstruction, or gastroparesis, occurs in $20 \%$ to $30 \%$ of patients following esophagogastric surgery and has significant morbidity [1]. Peroral endoscopic pyloromyotomy (POEP) has been reported in pigs [2] and recently in humans for the treatment of diabetic gastroparesis [3] or postoperative gastroparesis $[4,5]$. We report here two patients with delayed postoperative gastroparesis successfully treated by POEP.

Two male patients, 62 and 54 years of age, underwent esophagogastrectomy and laryngopharyngectomy with gastric pullup for esophageal and laryngeal cancer, respectively. One patient at 18 months and the other at 24 months after surgery presented with recurrent postprandial vomiting and regurgitation that did not respond to prokinetic drugs. Endoscopy in each patient revealed a solid food residue after 12 hours of fasting and a tight pylorus that resisted passage of the endo-

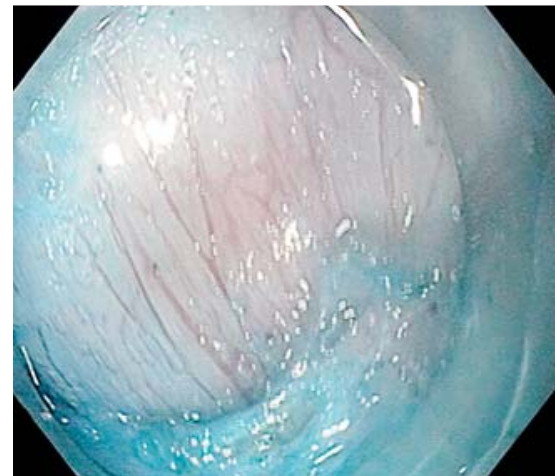

Fig. 2 View of the pyloric ring and duodenal mucosa through the submucosal tunnel.

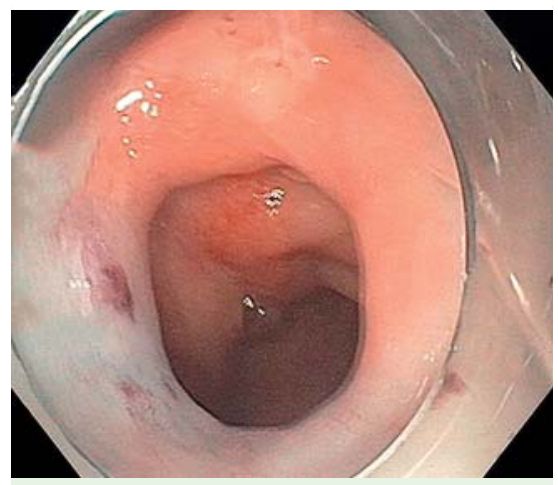

Fig. 5 Open pylorus following pyloromyotomy.

scope ( $\bullet$ Fig. 1 ). Barium studies showed delayed gastric emptying ( $>4$ hours).

Both patients underwent POEP while under general anesthesia with endotracheal intubation. Submucosal elevation was achieved by injecting normal saline stained with indigo carmine. A 2-cm mucosal incision on the greater curvature $7 \mathrm{~cm}$ proximal to the pylorus was made with triangular tip and insulated-tip knives (Olympus, Tokyo, Japan). A submucosal tunnel toward the pylorus was created by using ENDO CUT I and SOFT COAG modes (ERBE Vio 200 D; ERBE Elektromedizin, Tübingen, Germany). The pyloric muscular ring was identified by the bluestained duodenal mucosa and submucosa beyond it ( $\bullet$ Fig. 2 ) and, using the insulated-tip knife applied in a distal-to-proximal direction to prevent inadvertent duodenal mucosal injury, its full thickness was divided ( $\bullet$ Fig. 3 ). The myotomy was extended for $3 \mathrm{~cm}$ on the gastric side. The mucosal

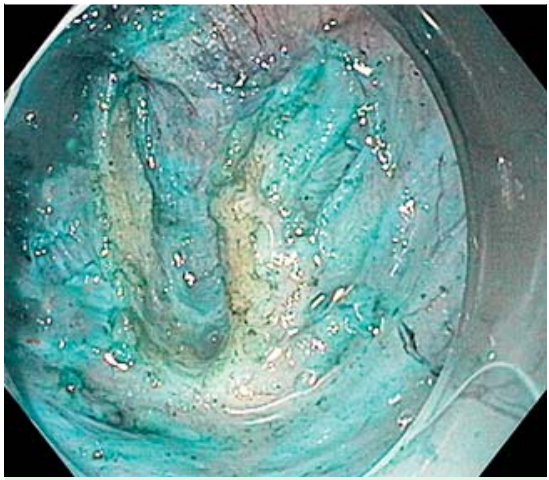

Fig.3 Pyloromyotomy.

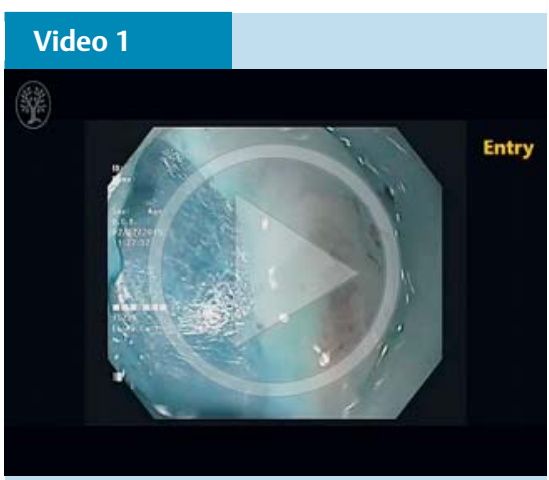

Endoscopic peroral pyloromyotomy step by step. After submucosal elevation, a mucosal incision is taken 5 to $7 \mathrm{~cm}$ proximal to the pylorus. A submucosal tunnel is created, and the pyloric ring is identified. The ring is divided vertically $3 \mathrm{~cm}$, and the mucosal incision is closed with endoclips.

incision was closed with endoclips (Ezee Clip; Olympus) ( Fig.4). A patulous pylorus and easy passage of the endoscope confirmed adequacy of the procedure ( $\bullet$ Fig. 5, $\bullet$ Video 1).

After 24 hours of fasting, an oral diet was established after the transit of contrast across the pylorus had been confirmed on fluoroscopy. At 4-week follow-up, each patient reported no episodes of regurgitation and had gained weight. A repeat endoscopy showed an open, easily passable pylorus.

Endoscopy_UCTN_Code_TTT_1AO_2AN

Competing interests: None 


\section{Amol Bapaye, Nachiket Dubale, Rajendra Pujari, Amol Kulkarni, Rucha Jajoo Naval, Viral Vyas, Mahesh Mahadik}

Deenanath Mangeshkar Hospital and Research Center, Shivanand Desai Center for Digestive Disorders, Pune, Maharashtra, India

\section{References}

1 Lanuti M, de Delva PE, Wright CD et al. Postesophagectomy gastric outlet obstruction: role of pyloromyotomy and management with endoscopic pyloric dilatation. Eur J Cardiothorac Surg 2007; 31: 149-153
2 Kawai M, Peretta S, Burckhardt $O$ et al. Endoscopic pyloromyotomy: a new concept of minimally invasive surgery for pyloric stenosis. Endoscopy 2012; 44: 169-173

3 Khashab MA, Stein E, Clarke JO et al. Gastric peroral endoscopic myotomy for refractory gastroparesis: first human endoscopic pyloromyotomy (with video). Gastrointest Endosc 2013; 78: 764-768

4 Chung H, Dallemagne B, Perretta $S$ et al. Endoscopic pyloromyotomy for postesophagectomy gastric outlet obstruction. Endoscopy 2014; 46 (Suppl. 01) UCTN: E345E346

5 Shlomovitz E, Pescarus R, Cassera MA et al Early human experience with per-oral endoscopic pyloromyotomy (POP). Surg Endosc 2015; 29: 543-551
Bibliography

DOI http://dx.doi.org/

10.1055/s-0034-1393368

Endoscopy 2015; 47: E581-E582

(c) Georg Thieme Verlag KG

Stuttgart · New York

ISSN 0013-726X

Corresponding author

\section{Amol Bapaye, MD}

Shivanand Desai Center for Digestive Disorders Deenanath Mangeshkar Hospital and Research Center

Pune

India

Fax: +91-20-4015-1969

amolbapaye@gmail.com 